Original Article

\title{
CLINICAL PHARMACIST-LED PROGRAM ON MEDICATION RECONCILIATION AND PATIENT COUNSELING IN THE DEPARTMENT OF GASTROENTEROLOGY
}

\author{
U. KRUTHIKA, M. SUDHASREE, J. MOUNIKA, N. TANDAVA KRISHNA, M. DIVYA, A. RAJANI*, G. RAVI ${ }^{1}$
}

Department of Pharmacy Practice, MNR College of Pharmacy, Sangareddy, TS, India, ${ }^{1}$ Department of Pharmaceutics, MNR College of Pharmacy, Sangareddy, TS, India

Email: adepurajani05@gmail.com

Received: 14 Oct 2019, Revised and Accepted: 26 Nov 2019

\section{ABSTRACT}

Objective: To study the effects of medication reconciliation and patient counseling on the overall health benefits of the patients in the department of gastroenterology.

Methods: This study is a prospective interventional study, was conducted in a 500 bedded MNR Hospital. The sample size taken was 150 patients and the study population comprised of patients aged 18-80 y, admitted in the hospital during the study period of six months.

Results: Out of 150 patients, there were 98 (65.33\%) male patients and 52 (34.67\%) female patients. Patients between 18 and 30 y of age were 29(19.33\%), between the age of 30 and 50 y were $71(47.33 \%)$ and above 50 were $50(33.33 \%)$. Pancreatitis was most prevalent with $21 \%$ of total prevalence, followed by CLD and cholelithiasis with 17\%, then IBD 16\%, PUD and Gastritis 5\%, GERD 4\% and other diseases 15\%.

Conclusion: The basic role of the pharmacist, is to help in minimizing the errors and to perform medication reconciliation. In patient counseling, pharmacists provide information about the disease, and the medications to increase patient safety and the changes in the behavior for the better outcome.

Keywords: Medication reconciliation, Patient counseling, Transition of care, Gastroenterology, Prospective, Interventional, Duplications, Errors

(C) 2020 The Authors. Published by Innovare Academic Sciences Pvt Ltd. This is an open-access article under the CC BY license (http://creativecommons.org/licenses/by/4.0/) DOI: http://dx.doi.org/10.22159/ijpps.2020v12i1.36085. Journal homepage: https://innovareacademics.in/journals/index.php/ijpps

\section{INTRODUCTION}

Gastroenterology is the study of the normal function and diseases of the esophagus, stomach, small intestine, colon, and rectum, pancreas, gall bladder, bile ducts and liver. In essence, all the normal activities and diseases of the digestive organs are part of the study of gastroenterology $[1,2]$.

Patients often receive new medications or have changes made to their existing medications at times of transitions in care-upon hospital admission, transfer from one unit to another during hospitalization, or discharge from the hospital to home or another facility. Although most of these changes are intentional, unintended, changes occur frequently for a variety of reasons. For example, hospital-based clinicians might not be able to easily access the patient's complete pre-admission medication lists, or maybe unaware of recent medication changes. As a result, the new medication regimen prescribed at the time of discharge may inadvertently omit needed medications, unnecessarily duplicate existing therapies, or contain incorrect dosages. These discrepancies place patients at risk for adverse drug events (ADEs), which have been shown to be one of the most common types of adverse events after hospital [3, 4].

Medication reconciliation refers to the process of avoiding such inadvertent inconsistencies across transitions in care by reviewing the patient's complete medication regimen at the time of admission, transfer, and discharge and comparing it with the regimen being considered for the new setting of care. This reconciliation is done to avoid medication errors such as omissions, duplications, dosing errors and drug interactions. It should be done at every transition of care in which new medications are ordered or existing orders are rewritten $[5,6]$.

The National Patient Safety Goal requires the organizations "maintain and communicate accurate medication information" and "compare the medication information the patient brought to the hospital with the medications ordered for the patient by the hospital in order to identify and resolve discrepancies $[7,8]$.
Patient counseling refers to the process of providing information, advice and assistance to help patients use their medication appropriately. The information and advice are given by the pharmacist directly to the patients or to the patient's representatives, and may also include information about the patient's illness or recommended lifestyle changes. The information is usually given verbally, but maybe supplemented with written materials. Good communication skills are required to gain the patient's confidence and to motivate the patient to adhere to the recommended regimen [9-11].

\section{MATERIALS AND METHODS}

The research was a prospective pharmacist interventional study conducted over a period of 8 mo at MNR Hospital, sangareddy, Telangana state after considering the inclusion and exclusion criteria. The sample size was 150 patients and the study population comprised of patients aged $18 \mathrm{y}$ and above. The patient's Best Possible Medication History (BPMH) was taken and the medication reconciliation was done from the patient's case sheet at all interfaces of patient care. The patient involved the study were provided appropriate patient counseling about the disease, drug use and life style changes.

The medication reconciliation process was done in three major steps are a collection of an accurate medication list, clarification of any questions about drug, dose, frequency and communication with physician about any identified queries.

The patient counseling process was done in three steps are assessment and prioritizing needs, implementation of the advice process and follow up and evaluation.

\section{Analysis of data}

The data collected from the study were tabulated to obtain bar diagrams, pie charts and to draw percentages.

\section{Ethical clearance}

The present study was carried out after obtaining ethical clearance from the institutional ethics committee. Privacy and confidentiality were maintained in patient-related information during execution of 
clinical care services. No. of Participants in the study were 150 patients and approval Number is IEC/MNRP/Prot/2019/003.

\section{RESULTS AND DISCUSSION}

Medication reconciliation process at patient hospitalization, transition and discharge follow up improved medication reconciliation accuracy and care of hospitalized patients led to safer transition to the ambulatory settings. Medication error identification is the main target for improving clinical practice.

The total number of patients involved in our study were 150 . The number of male patients were $98(65.33 \%)$ and the number of female patients were $52(34.67 \%)$ and are better illustrated using bar diagram. From the results obtained it was found out that male patients are more prone to the diseases than females in the gastroenterology department during the period of our study. The data was depicted in the form of bar diagram in fig. 1.

The total number of patients taken were 150 . Out of these it was found that about 29 (19.33\%) patients are involved with age group of $20-40$ y followed by $71(47.35 \%)$ patients are involved in age group of 40-60 y and 50(33.33\%) patients in the age group of 60-80 $\mathrm{y}$ old. The data was depicted in the form of bar diagram in fig. 2.

Out of 150 patients, 32(21\%) patients were diagnosed with Pancreatitis, 25(17\%) patients were diagnosed with Chronic Liver Disease, $25(17 \%)$ patients were diagnosed with cholelithiasis, $23(15 \%)$ patients were diagnosed with Inflammatory Bowel Disease, $23(15 \%)$ patients were diagnosed with other conditions of disease, $8(5 \%)$ patients were diagnosed with gastritis, $8(5 \%)$ patients were diagnosed with Peptic Ulcer Disease and 6(4\%) patients were diagnosed with GERD. Out of these diseases, pancreatitis is more prevalent when compared to other gastrointestinal diseases. The data was depicted in the form of pie diagram of fig. 3 .

From 150 study population, the medication reconciliation was done and found 341 discrepancies from various factors. Among the factors, the drug interactions were found about 167(48.9\%), prescribing errors were found to be about 60(7.5\%), therapeutic duplications were found to be about 52(15.2\%), dosage errors were found to be about $46(13.48 \%)$ and omission errors were found to be about $16(4.6 \%)$. Out of which the drug interactions were found to be more in prescriptions. The data was depicted in the form of bar diagram in fig. 4 .

The above table shows the type of severity found in the total number of discrepancies in which the moderate type of discrepancies was found to be the highest 183(53.66\%). Minor and major discrepancies were 93(27.27\%) and 65(19.06\%) respectively. The data was tabulated in table no: 5 and depicted in the form of pie diagram in fig. no: 5 . The above table shows the type of severity found in the total number of discrepancies in which the moderate type of discrepancies was found to be the highest 183(53.66\%). Minor and major discrepancies were $93(27.27 \%)$ and $65(19.06 \%)$ respectively. The data was tabulated in table 1 and depicted in the form of pie diagram in fig. 5 .

From this table most of the discrepancies found were unintended $274(80.35 \%)$ during the course of hospitalization. And the intended discrepancies were $67(19.65 \%)$. As unintended discrepancies were more adverse drug events can be reduced significantly. The data was tabulated in table 2 .

Out of these, $274(80.35 \%)$ discrepancies in $60(73.1 \%)$ patients are accepted. Followed by 67(19.65\%) discrepancies in 15(18.2\%) patients are not accepted and $0 \%$ of discrepancies in $7(8.5 \%)$ patients. Mean and standard deviation found to be 1.90667 and 0.935378 respectively. The data was tabulated in table 3 . The number of patients who attended for patient counselling were 150 , from which 136(90.66\%) patients were cooperative and 14(9.34\%) patients were non cooperative. Those who responded were benefitted. The data was depicted in fig. 7.

We followed a total of 136 patients out of which 100 patients responded to patient counselling, and 36 patients did not respond to patient counselling. Out of the 100 people who responded to patient counselling 86 patients improved their outcome of treatment. From the results it showed that most of the patients were benefitted from patient counselling and improved quality of life. Out of 150 patients, 74 patients received leaflets has counselling aids, 40 patients received pictograms, 34 patients were counselled verbally regarding disease and drug-based condition of the patient for better health care. The data was depicted in the form of bar diagram in fig. 8.

Clinical pharmacist is responsible to conduct complete medication history and provide information to the patient about the drug therapy which helps to recognize and utilize relevant clinical data to identify and resolve discrepancies such as therapeutic duplication, drug-drug interactions, inappropriate dosaging etc. With appropriate clinical care of patients by a clinical pharmacist could establish a level of attention and disease management which inturn results in better therapeutic outcome [12].

\section{Gender wise distribution of cases}

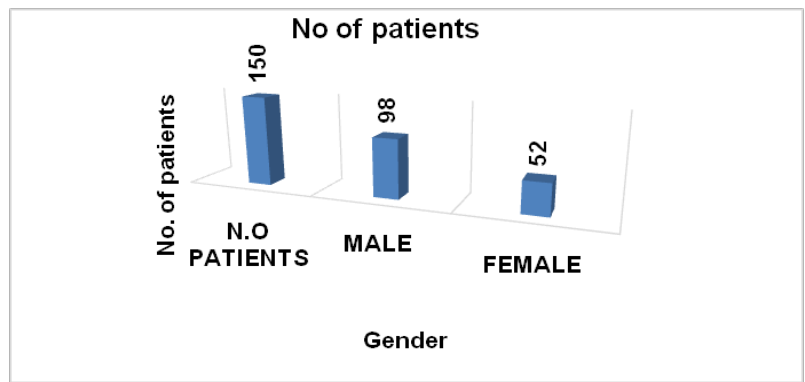

Fig. 1: Gender wise distribution of cases

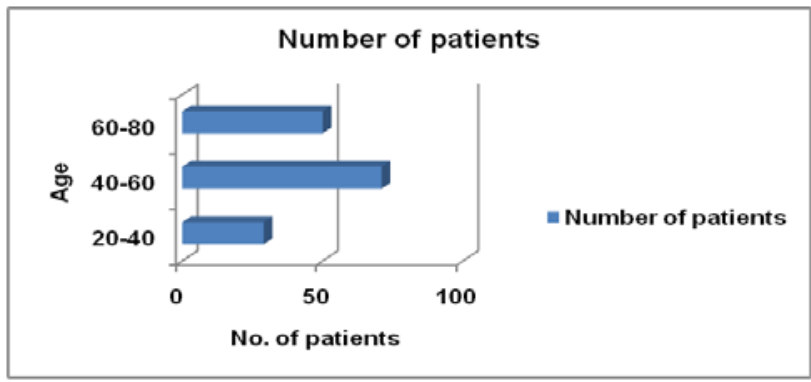

Fig. 2: Age wise distribution of cases 


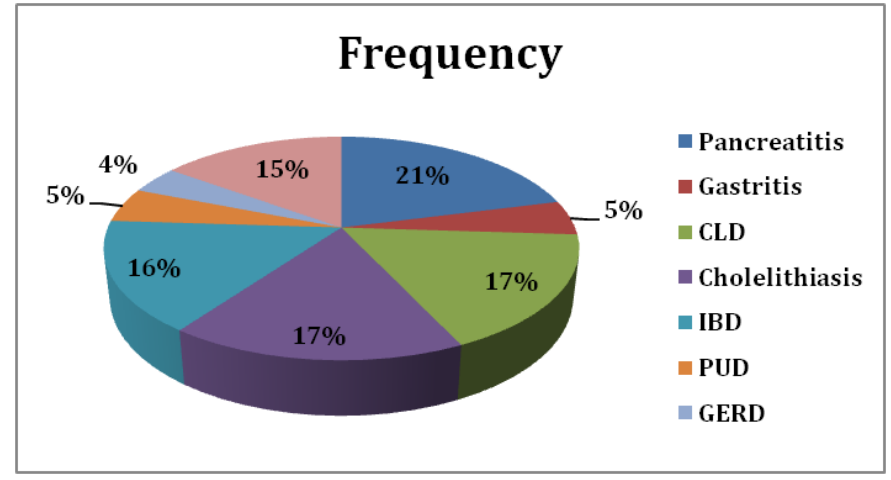

Fig. 3: Disease distribution of cases

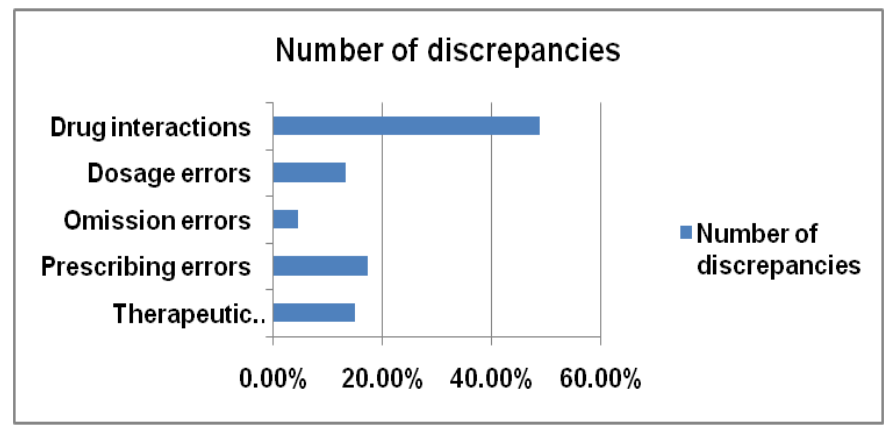

Fig. 4: Types of medication discrepancies

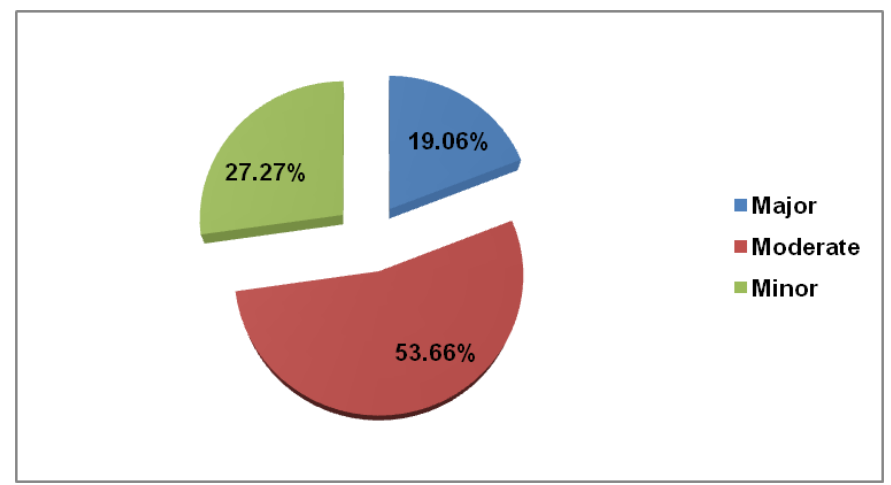

Fig. 5: Severity of discrepancies

Table 1: Severity of discrepancies

\begin{tabular}{lll}
\hline Severity & Number of discrepancies & percentage \\
\hline Major & 65 & $19.06 \%$ \\
Moderate & 183 & $53.66 \%$ \\
Minor & 93 & $27.27 \%$ \\
\hline
\end{tabular}

Table 2: Discrepancies

\begin{tabular}{lcl}
\hline Total discrepancies & Unintended discrepancies & Intended discrepancies. \\
\hline 341 & $274(80.35 \%)$ & $67(19.65 \%)$ \\
& & \\
\multicolumn{3}{l}{ Table 3: Physician acceptance rate } \\
\hline Medication discrepancies & Number of patients & Number of discrepancies \\
\hline No discrepancies & $07(8.5 \%)$ & $00(00 \%)$ \\
Number of discrepancies accepted & $60(73.1 \%)$ & $274(80.35 \%)$ \\
Number of discrepancies rejected & $15(18.2 \%)$ & $67(19.65 \%)$ \\
\hline
\end{tabular}




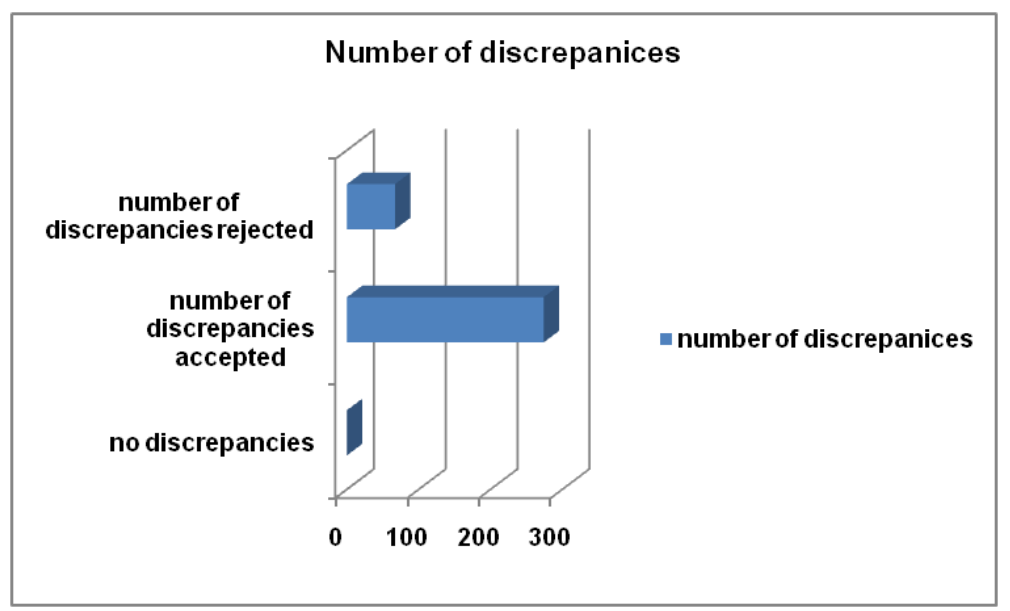

Fig. 6: Physician acceptance rate

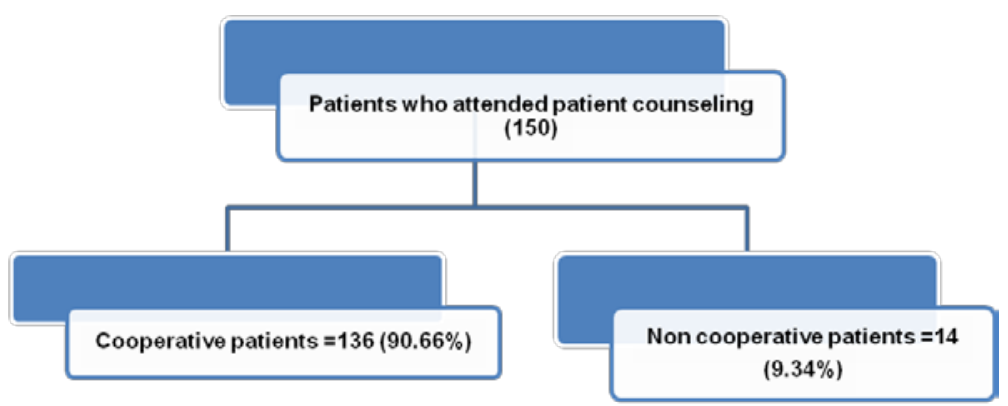

Fig. 7: Patient counseling

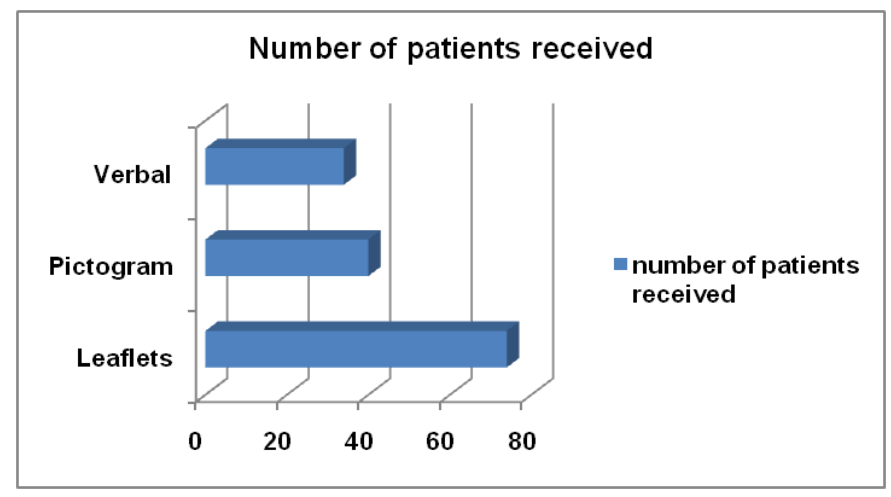

Fig. 8: Counselling aids used in patient counseling

\section{CONCLUSION}

The basic role of pharmacist, is to help in minimizing the errors and to perform medication reconciliation, which was shown to be an important tool in detecting the medication discrepancies and preventing adverse patient outcomes. Medication reconciliation is performed to avoid medication errors such as omissions, duplication, dosing errors, prescription errors or drug-drug interactions. In our study, the discrepancies were checked and reconciled by which the patient's quality of life was improved and the discrepancies were reduced. As most of discrepancies were accepted by the physician, it helped to resolve the errors.

\section{ACKNOWLEDGEMENT}

Authors are very thankful to the management of MNR Educational Trust and Medical Superintendent of MNR Hospital, Sangareddy for providing the facilities and enabling us to carry out the study and authors also are very much thankful to Dr. V. Alagarsamy, Professor and Principal, MNR College of Pharmacy, Sangareddy for his constant support and encouragement.

\section{FUNDING}

Nil

\section{AUTHORS CONTRIBUTIONS}

Kruthika U and Sudhasree M collected the case profiles. Mounika J and Tandava Krishna N compiled the collected information. Divya M was involved in the planning of the protocol and supervising the present study. Rajani A and Ravi G were involved in scientific editing, writing and communicating the manuscript to the journal.

\section{CONFLICT OF INTERESTS}

The authors declared no conflict of interest 


\section{REFERENCES}

1. Rey MB, Prados YA, Gomez ES. Analysis of the medication reconciliation process conducted at hospital admission Classification and variability of drug assessment reports on the GENESIS group. Farm Hosp 2016;40:246-59.

2. Layqah LA, Alakeel YS, Shamou JZ. The practice of counsellingin pharmacy: patients' perspectives. Asian J Res Pharm Sci 2018;8:170-6.

3. Ramadevi K, Kalyan VRL, Abeer RMA. A study on the effect of dietary factors on functional gastrointestinal disorders in women of hail region in Saudi Arabia. Asian J Pharm Clin Res 2018;11:202-7.

4. Vira T, Colquhoun M, Etchells E. Reconcilable differences: correcting medication errors at hospital admission and discharge. Qual Saf Health Care 2006;15:122-6.

5. Praveena P, Usman S, Deepika B, Kumar R, Mohanta GP, Manna $\mathrm{PK}$, et al. Impact of patient counselling on knowledge, attitude, practice and quality of life in patients with type ii diabetes mellitus and hypertension. Indian J Pharm Pract 2011;4:50-4

6. Accredidation Canada. Second edition. Toronto Swann publications Required organizational practices handbook; 2014
7. Mihajlovic S, Gauthier J, MacDonald E. Patient characteristics associated with adverse drug events in hospital: an overview of reviews. Canadian J Hospital Pharm 2016;69:294.

8. Lakshmi SS, Yashwanth GR, Hemapriyadarshini K, Veeramani G, Mudiyarasan K. Impact of patient counselling and medication adherence on tuberculosis patients. Int J Innov Pharm Sci Res 2015;3:221-31.

9. Mazhar F, Akram S, Al-Osaimi YA, Haider N. Medication reconciliation errors in a tertiary care hospital in Saudi Arabia: admission discrepancies and risk factors. Pharm Practice (Granada) 2017;15:864.

10. Mitchener $S$. The role of patient counsellingin preventing medication errors: Significance of graduation date; 2003. p. 1-9.

11. Van den Bemt PM, Van den Broek S, Van Nunen AK, Harbers JB, Lenderink AW. Medication reconciliation performed by pharmacy technicians at the time of preoperative screening. Ann Pharmacother 2009;43:868.

12. Francis J, Abraham S. Clinical pharmacists: Bridging the gap between patients and physicians. Saudi Pharm J 2014; 22:600-2. 